\title{
A Rare Reason in an Infant Who Presented With Recurrent Bleeding: Munchausen by Proxy Syndrome
}

\author{
Fatih Demircioglu ${ }^{\mathrm{a}, \mathrm{d}}$, Mervan Bekdas ${ }^{\mathrm{a}}$, Sevil Bilir Goksugur ${ }^{\mathrm{a}}$, \\ Cemalettin Gunes ${ }^{\mathrm{b}}$, Osman Yildirim ${ }^{\mathrm{c}}$
}

\begin{abstract}
Munchausen syndrome by proxy is a psychiatric condition and form of child abuse in which a caregiver, usually a mother, induces illness in a child to gain attention for herself. Here, we reported an 8-month-old girl who presented with spontaneous bleeding from ear, eye and gastrointestinal system. The girl was investigated thoroughly by pediatricians for all possible bleeding disorders, but there was no conclusive diagnosis. Munchausen syndrome by proxy was diagnosed with a multidisciplinary approach. For dinscriptive diagnosis of these patients, thinking about the Munchausen syndrome by proxy will decrease unnecessary examinations and it will prevent threated exploitation of lives of these children.
\end{abstract}

Keywords: Munchausen by proxy syndrome; Recurrent bleeding; Infant

\section{Introduction}

It is important to rule out the cases that predispose to bleeding in the children who present with recurrent hemorrhage symptom. In patients who present with superficial bleeding such as petechia, purpura, ecchymosis, mucosal and skin hemorrhage, thrombocytopenia and thrombocyte functional disorders are among important reasons that predispose to hemorrhage whereas in patients who present with hemor-

Manuscript accepted for publication April 26, 2014

\footnotetext{
${ }^{\mathrm{a}}$ Abant Izzet Baysal University, Faculty of Medicine, Department of Pediatrics, Bolu, Turkey

${ }^{\mathrm{b}}$ Duzce University, Faculty of Medicine, Department of Pediatrics, Duzce, Turkey

${ }^{c}$ Abant Izzet Baysal University, Faculty of Medicine, Department of Psychiatry, Bolu, Turkey

${ }^{\mathrm{d} C}$ Corresponding Author: Fatih Demircioglu, Abant Izzet Baysal University, Faculty of Medicine, Department of Pediatrics, Bolu,Turkey. Email: fatih_demircioglu@yahoo.com
}

doi: http://dx.doi.org/10.14740/jmc1289w rhage into deep tissue such as muscle, joint and central nervous system, the important reasons that predispose to hemorrhage include von Willebrand disease and other coagulation factors $[1,2]$.

Munchausen by proxy syndrome (MBPS: disease by proxy) is a special form of child abuse. It is the case when a disease develops in a child due to the parent or the caregiver. The children are taken to the doctor several times for these symptoms and are subject to unnecessary interventions [3]. In the literature, situations such as recurrent vomiting episodes, apnea attaches, administration of drugs by the caregiver, recurrent hypoglycemia attacks specially after the use of insulin and drug intoxications have been reported [4-6]. Additionally, cases have also been defined who presented with symptoms including recurrent hematuria, hemoptysis, ear and gastrointestinal system bleeding, who were identified to have no pathologies as a result of many laboratory studies performed to investigate predisposition to bleeding and other etiologies and were diagnosed with MBPS [7, 8].

To draw attention to this topic, we would like to present an MBPS case of an 8-month-old girl, who presented due to recurrent nose, ear, eye and gastrointestinal system hemorrhages and on whom no pathologies were identified in the laboratory examinations performed.

\section{Case Report}

An 8-month-old female patient presented to our hospital due to hemorrhage in ear, nose and stools that had been going on for a few days. She was reported as having intermittent hemorrhages in the nose, ear and eye for 2 months, and blood started to be seen in her stools and vomit; no pathologies were determined as a result of her pathological studies. In her anamnesis, it was seen that she was born in normal term with a weight of $2,750 \mathrm{~g}$ and she stayed for 5 days in the incubator. In terms of her family history, there were no particularities other than the history of bleeding in the nose and mouth of her mother during pregnancy. At physical examination, her body weight was $7,600 \mathrm{~g}(10-25 \mathrm{p})$, height 70 $\mathrm{cm}(10-25 \mathrm{p})$, head perimeter $43 \mathrm{~cm}(25 \mathrm{p})$, fever $36.8^{\circ} \mathrm{C}$, pulse rate $136 / \mathrm{min}$ and respiratory rate $24 / \mathrm{min}$. Her general 
condition was good, she was lively-active and interested in her surroundings. There were coagulums on the outer part of her ear and front part of her nose. The external ear canal and tympanic membrane were normal. There were no active hemorrhages. Similarly, no hemorrhage sites were identified in the inner part of the nose. The eye examination was performed since intermittent bleeding in the eye was described, and the examination result was normal.

In full blood count, the white spheres measured as $10,600 / \mathrm{mm}^{3}$, hemoglobin $10.2 \mathrm{~g} / \mathrm{dL}$, hematocrit $28.9 \%$, MCV 69.2 fL, RDW $16.3 \%$, RBC $4.42 \times 10^{6} / \mu \mathrm{L}$, platelet $404,000 / \mathrm{mm}^{3}$; renal and hepatic function tests had normal results. The platelets were abundant and clustered in the peripheral blood smear test. Prothrombin time was $13 \mathrm{~s}$; activated partial thrombo-plastin time was $29.3 \mathrm{~s}$; fibrinogen was $462 \mathrm{mg} / \mathrm{dL}$. The results of full urinalysis, occult blood in stool and ferritin tests were normal. The bleeding time test result was $4.5 \mathrm{~min}$. Furthermore, it was seen that the results of the collagen-epinephrine test conducted with PFA-100, the collagen-ADP test (104 s and $97 \mathrm{~s}$, respectively), dissolution of coagulum in 5 molar urea and factor- 13 antigen level were within normal limits.

It was seen that the symptoms were repeated in the follow-ups and the repeated laboratory tests were persistently normal. MBPS was considered. It was observed that the baby had no symptoms of hemorrhage upon separation from the mother. Therewith, consultation from a psychiatrist was asked for from the parent. During the interview conducted with the parent, it was learned that there was a problem between the mother and the mother-in-law and that was the reason why the mother resorted to this method. Following the psychiatric examination and tests that the mother underwent, signs that supported the MBPS were identified and the mother was scheduled for follow-up. The patient was discharged after being scheduled for control visits at related departments.

\section{Discussion}

Asher diagnosed a group of adult patients, who went from one hospital to another causing several surgical interventions to be performed on themselves with the Munchausen syndromes [9]. For MBPS, it is known that a caregiver of a child voluntarily attributes signs of fabricated or artificial disease to the child. In the most frequently observed type of MBPS, the person who attributes the disease to the child is the mother who has marital problems or psychiatric problems $[3,10]$. In the case of our patient, it was learned that the mother had problems with the mother-in-law who was living in the same house; therefore, the mother resorted to this way in order to get away from the house and attract attention.

With MBPS, the child suffers from damage as a result of the diagnostic and therapeutic procedures or the disease triggered by the parent. This disease should be considered in the presence of unexplainable signs in the child and if these signs appear only when the child is with the parent. The aim here is not to harm or punish the child, but to point out to the importance of the parent $[11,12]$. Our patient also presented to different health institutions many times with history of repeated, multi-site bleeding and several studies were performed on her. Furthermore, the most important sign supporting the diagnosis was that the bleeding signs disappeared when the mother was drawn away from the child.

Persons who have behavioral problems trigger severe health problems such as causing anemia by collecting blood from themselves or from the person they care for, causing hypoglycemia by injecting insulin, transmitting microorganisms to his/her body via injection, opening the wounds in the surgical site following surgery in order to adopt the role of a patient and to attract attention $[3,10,12]$. Furthermore, presentations in a wide spectrum have been reported including allergic disease, fever, dermatitis artefacta, bacterial infections, osteomyelitis, epilepsy or neurological disorders, gastrointestinal system disorder, renal disease, artificial bleeding, apnea, cardio-pulmonary arrest and death $[13,14]$.

In addition to the above-mentioned clinical symptoms, MBPS cases may also present due to repeated bleeding complaints. The bleeding symptoms that may be seen in these patients may be in the form of hemoptysis, gastrointestinal system bleeding, vaginal hemorrhage, hematuria, bleeding from the eye and ear or easy bruising/ecchymosis $[7,8,15$, 16]. Tufekci et al [7] identified in their study that there were symptoms of repeated hemoptysis, hematuria, bleeding from the nipple and bloody tear; however, there were no laboratory findings to account for this clinical picture according to all laboratory studies. During the detailed psychiatric examination, the mother was observed to suffer from an Axis I disorder. Tsai et al [8] demonstrated in their study that the reason for recurrent hematuria could not be found in spite of several laboratory studies in the sisters who were respectively diagnosed with the basal membrane disease and epithelioid angiomyolipoma; however, the tandem DNA analysis conducted on the urine showed that the blood pertained to the mother. In our patient, all the laboratory examination results were normal in spite of the fact that bleeding symptoms were defined in many organs such as eye, ear, nose and gastrointestinal system. It was seen that all the symptoms disappeared after the mother was distanced from the baby.

MBPS is seen relatively frequently; however, it may be overlooked if it is not considered and it may cause many invasive interventions on the baby, and it may even cause the death of the baby in some instances. Therefore, MBPS should definitely be considered in differential diagnosis for children who have strange and unexplainable symptoms. Thus, it would be possible to prevent several unnecessary studies, wrong treatment deliveries and unneeded hospitalizations and to prevent waste of labor, cost and time. 


\section{References}

1. Celkan, T, Yilmaz, I, Demirel, A, Cam, H, Karaman, S, Dogru, O, Apak, H, Ozkan, A, Tastan, Y, and Yildiz, I. Cocuk acil servisinde kanama nedenleri. Turk Pediatri Arsivi. 2006;41:146-150.

2. Berntorp E, Halimeh S, Gringeri A, Mathias M, Escuriola $\mathrm{C}$, Perez R. Management of bleeding disorders in children. Haemophilia. 2012;18(Suppl 2):15-23.

3. Squires JE, Squires RH, Jr. Munchausen syndrome by proxy: ongoing clinical challenges. J Pediatr Gastroenterol Nutr. 2010;51(3):248-253.

4. Griffiths H, Cuddihy PJ, Marnane C. Bleeding ears: a case of Munchausen syndrome by proxy. Int J Pediatr Otorhinolaryngol. 2001;57(3):245-247.

5. Shaw RJ, Dayal S, Hartman JK, DeMaso DR. Factitious disorder by proxy: pediatric condition falsification. Harv Rev Psychiatry. 2008;16(4):215-224.

6. Kucuker H, Demir T, Oral R. Pediatric condition falsification (Munchausen syndrome by Proxy) as a continuum of maternal factitious disorder (Munchausen syndrome). Pediatr Diabetes. 2010;11(8):572-578.

7. Tufekci O, Gozmen S, Yilmaz S, Hilkay Karapinar T, Cetin B, Burak Dursun O, Emiroglu N, et al. A case with unexplained bleeding from multiple sites: munchausen syndrome by proxy. Pediatr Hematol Oncol. 2011;28(5):439-443.
8. Tsai HL, Yang LY, Chin TW, Chen PH, Yen HJ, Liu CS, Wang HH, et al. Child abuse in medical setting presenting as gross hematuria: diagnosis by DNA short tandem repeats. Pediatrics. 2012;130(1):e224-229.

9. Asher R. Munchausen's syndrome. Lancet. 1951;1(6650):339-341.

10. Hughes LM, Corbo-Richert B. Munchausen syndrome by proxy: literature review and implications for critical care nurses. Crit Care Nurse. 1999;19(3):71-78.

11. Jain AM. Emergency department evaluation of child abuse. Emerg Med Clin North Am. 1999;17(3):575-593,v.

12. Tercier A. Child abuse. In: Maer JA, editor. Emergency Medicine, 4th edition. St. Louis: Mosby; 1998:11081118.

13. Giurgea I, Ulinski T, Touati G, Sempoux C, Mochel F, Brunelle F, Saudubray JM, et al. Factitious hyperinsulinism leading to pancreatectomy: severe forms of Munchausen syndrome by proxy. Pediatrics. 2005;116(1):e145-148.

14. Denny SJ, Grant CC, Pinnock R. Epidemiology of Munchausen syndrome by proxy in New Zealand. J Paediatr Child Health. 2001;37(3):240-243.

15. Bennett AM, Bennett SM, Prinsley PR, Wickstead M. Spitting in the ear: a falsified disease using video evidence. J Laryngol Otol. 2005;119(11):926-927.

16. Taylor D. Unnatural eye injuries. Trans Med Soc Lond. 2001;118:43-53. 